\section{A Sensitive Method for the Detection of Traces of Water in Oil}

Where electrical components are immersed in oil as in transformers or servo systems, dissolved water even in traces may have an adverse effect on insulation material, especially if air (to supply oxygen) and a metal (such as copper, to act as a catalyst) are present as well. It therefore becomes important to know if water is present and, if so, how much.

What is apparently a new and sensitive method of measuring the water content of oil has been discovered in this laboratory. The method relies on the fact that perfectly dry air, arranged to stand over a 'wet' oil, will take up moisture from the oil until the partial relative humidity of the air (at the prevailing room temperature) is the same as the volume concentration of the water in the oil.

A 'humidiscope' has been devised to determine this partial humidity. It consists of a metal tube $4 \mathrm{in}$. long by 1 in. bore arranged to stand vertically; the bore is divided into an upper chamber of approximately $40 \mathrm{ml}$. capacity and a smaller, lower one by a pipeclay diaphragm; the top chamber contains a wiremesh 'chip-basket' holding a powerful desiccant such as $1 / 8 \mathrm{in}$. cubes of freshly dried porous calcium chloride; a glass plate is waxed on to the top of the tube to effect closure. The lower, smaller chamber has the air in it also brought to zero relative humidity by standing over a 'drying pit' (containing the same desiccant) in a metal base; an oil manometer connected to the two chambers gives a zero reading when both are at zero relative humidity. A thin mica strip is then slid under the instrument, which is slid bodily sideways to cover a second 'pit', filled to the brim with the oil sample; this procedure prevents any atmospheric air (and its associated moisture) from getting into the lower chamber. Moisture then diffuses from the oil surface into the dry air in the lower chamber and the relative humidity established causes a differential pressure head across the porous diaphragm which is indicated by the manometer.

It has been shown ${ }^{1}$ that the vapour pressure $p$ in $\mathrm{mm}$. mercury is

$$
p=\rho \sqrt{\frac{R T}{2 \pi m}},
$$

where $R$ is the gas constant $\left(1.372 \times 10^{-16}\right), T$ is absolute temperature $\left({ }^{\circ} \mathrm{C}.\right), \rho$ is $\mathrm{gm} . / \mathrm{ml}$. vapour in air, $m$ is mass of a water molecule.

If the saturated vapour pressure of water at the temperature of the experiment is $p_{\text {sat }} \mathrm{mm}$. mercury, then $p_{\text {sat }} \propto 100$ (relative humidity). Further, from Graham's law,

$$
\frac{v_{1}}{v_{2}}=\frac{\sqrt{\rho_{2}}}{\sqrt{\rho_{1}}}
$$

where $v$ is the rate of diffusion through a porous membrane.

From this,

$$
\frac{p_{1}^{2}}{p_{2}{ }^{2}}=\frac{p_{2}}{P_{1}}
$$

where $p$ is the vapour pressure associated with the vapour density $p$.

Hence the relative humidity of the air above the wet oil may be expressed as

$$
R H=\frac{p^{2}}{\left(p_{\text {sat }} \times 13.6 \times \frac{1}{0.871}\right)^{8}},
$$

where 0.871 is the specific gravity of the oil used in the manometer; $p_{\text {sat }}$ is obtained from tables of water vapour pressure.

\begin{tabular}{|c|c|c|c|}
\hline Test No. & Oil & $\begin{array}{c}\text { Wetness by } \\
\text { humidiscope } \\
(\%)\end{array}$ & $\begin{array}{c}\text { Wetness by } \\
\text { carbide test } \\
(\%)\end{array}$ \\
\hline 1 & $O M .13$, a very light & $0 \cdot 08 \mathrm{i}$ & $\begin{array}{ll}\text { (a) } & 0 \cdot 09 \\
\text { (b) } & 0 \cdot 12\end{array}$ \\
\hline 2 & $\begin{array}{l}\text { OM. } .35 \text {, a light mineral } \\
\text { oil as used for servo } \\
\text { mechanisms }\end{array}$ & (a) 0.28 & $0 \cdot 19$ \\
\hline 3 & Castor oil. (BP quality) & $\begin{array}{l}\text { (a) } 1 \cdot 13 \\
\text { (b) } 1.20\end{array}$ & (a) $1 \cdot 25$ \\
\hline 4 & Olive oil (BP quality) & $\begin{array}{l}\text { (a) } 0.26 \\
\text { (b) } 0.33\end{array}$ & \\
\hline
\end{tabular}

Tests are still in progress, but some results which have been obtained are given in the accompanying table.

These four oils were clear and 'bright' and it came as a surprise that they contained so much dissolved water.

In general, it has been found that the carbide test may not always be reliable for mineral oils as these often contain addition agents; certain mineral oils give results that are much too high, and it is thought this may be due to side-reactions involving the addition agents.

It is intended to publish a fuller account of this work later when it has been completed.

I am indebted to the manager of this laboratory, Lieut.-Cdr. J. R. D. Walker, for permission to make this communication.

Experimental Oil Test Group,

Research Department,

Vickers-Armstrongs, Ltd., Elswick Works,

Newcastle upon Tyne 4. Oct. 12.

${ }^{1}$ Adam, N. K., "Physics and Chemistry of Surfaces", 6 (1941).

\section{Rotation of the Eyes during Involuntary Blinking}

IT is apparent from a review in Nature by Lawson ${ }^{1}$ that there are few published data on movements of the eyes during blinking. In the course of a more general investigation on eye movements ${ }^{2}$, I have recently obtained several records of rotations of the eye during blinking. The records are made by photography of a beam of light reflected from a small flat worked on a contact lens.

Evidence has been obtained that the lens follows the eye movements precisely and does not affect their velocity. On most occasions the lids remain sufficiently far apart during the blink to leave the flat at least partly unobscured. The horizontal and vertical components of the rotations of the eyes during the blink may therefore be deduced from the records. These show that the eye moves simultaneously inwards and upwards through angles of about 20-100 min. of are inwards ( 15 blinks, two subjects) and $40-70 \mathrm{~min}$. of arc upwards (5 blinks, two subjects) : the movement occupies 0.04-0.09 sec. The times for the two eyes are identical; but the magnitude of the angular movements may be widely different. The return movement to the original 